\title{
Reference intervals for the echocardiographic measurements of the right heart in children and adolescents: a systematic review
}

\author{
Carolina E Lemmer (Hunsinger) ${ }^{1 *}$, Mark E Engel ${ }^{1}$, John C Stanfliet ${ }^{2}$ and Bongani M Mayosi ${ }^{1}$
}

\begin{abstract}
Background: Transthoracic echocardiography is the primary imaging modality for the diagnosis of right ventricular (RV) involvement in congenital and acquired heart diseases. There is increasing recognition of the contribution of RV dysfunction in heart diseases affecting children and adolescents, but there is insufficient information on reference intervals for the echocardiographic measurements of the right heart in children and adolescents that represent all the continental populations of the world.
\end{abstract}

Objective: The aim of this systematic review was to collate, from published studies, normative data for echocardiographic evaluation of the right heart in children and adolescents, and to identify gaps in knowledge in this field especially with respect to sub-Saharan Africans.

Methods: We performed a systematic literature search to identify studies of reference intervals for right heart measurements as determined by transthoracic echocardiography in healthy children and adolescents of school-going age. Articles were retrieved from electronic databases with a combination of search terms from the earliest date available until May 2013.

Results: Reference data were available for a broad range of variables. Fifty one studies out of 3096 publications were included. The sample sizes of the reference populations ranged from 13 to 2036 with ages varying from 5 to 21 years. We identified areas lacking sufficient reference data. These included reference data for determining right atrial size, tricuspid valve area, RV dimensions and areas, the RV \% fractional area change, pulmonary artery pressure gradients and the right-sided haemodynamics, including the inferior vena cava dimensions and collapsibility. There were no data for sub-Saharan African children and adolescents.

Conclusion: Reliable reference data are lacking for important echocardiographic measurements of the RV in children and adolescents, especially for sub-Saharan Africans.

Keywords: Echocardiography, Reference ranges, Normal values, Right ventricle, Right atrium, Tricuspid, Pulmonary, Vena cava, Paediatric

\section{Introduction}

Transthoracic echocardiography is the primary imaging modality for the diagnosis of right ventricular (RV) failure [1-4]. Besides aiding in the diagnosis of conditions such as arrhythmogenic right ventricular cardiomyopathy, pulmonary embolism, and RV infarction, echocardiography plays a critical role in the diagnosis of congenital

\footnotetext{
* Correspondence: caroliseclintech@yahoo.com

'Department of Medicine, University of Cape Town and Groote Schuur Hospital, Observatory, Cape Town, South Africa

Full list of author information is available at the end of the article
}

heart diseases where the RV often serves as the main pumping chamber [5-8].

The absence of reference intervals for cardiac structures in children and adolescents is an important problem [6]. Publications dedicated to the echocardiographic study of the right heart, especially on reference values of the structure and function of the right heart in children and adolescents are scarce. Many of the previous studies had limited sample sizes, and were conducted predominantly in North American and European populations. Thus there is potential for interpretation errors when assessing 
African children, given that environmental, social, economic and other factors may influence the anthropometric standards of a population [9].

Systematic reviews provide rigorous, objective evidence to assess the literature through the use of a prespecified protocol and access a variety of database search engines. The use of explicit, systematic methods in reviews limits bias and reduces the effects of chance, providing more reliable results [10]. The aim of this systematic review was to collate, from published studies, normative data for echocardiographic evaluation of the right heart in children and adolescents, in order to identify gaps in knowledge in this field, especially with respect to the available of information on sub-Saharan African children.

\section{Methods}

\section{Types of studies}

This review considered all publications reporting reference values for the right heart in healthy children and adolescents determined by echocardiography.

\section{Types of reference individuals}

Participants included school children and adolescents with no history or echocardiographic evidence of heart disease. No exclusion was set on sample sizes of the studies.

\section{Inclusion and exclusion criteria}

Inclusion criteria:

- Age range from 5 to 21 years.

- Documentation of age and/or an indicator body size for reference individual(s). Indicators of body size included height and/or weight and/or body mass index (BMI) and/or body surface area (BSA).

- Presentation of results as one reference value and/or -interval for the whole sample or, in relation to age and/or body size.

- Availability of English version of paper in the case of foreign-language articles.

Exclusion criteria:

- Preterm infants.

- Deceased participants (autopsy studies).

- Participants with known cardiovascular disease.

- Measurements taken at high altitude $\geq 2400$ metres above sea level.

- Age groups including adults (without subgroups for participants younger than 22 years).

- Presentation of reference values that had already been included in a previously published article.

\section{Search strategy and selection of studies}

Figure 1 details the process by which articles were selected for inclusion.

The scope of search aimed to include all published work dating back to the start of routine echocardiography. We searched the Pubmed and ISI Web of Knowledge databases with a combination of the following search terms: ECHOCARDIOGRA* [Title/Abstract] AND ("NORMAL VALUES" [Title/Abstract]) OR ("NORMAL RANGES" [Title/ Abstract]) OR ("REFERENCE VALUES"[Title/Abstract]) OR ("REFERENCE RANGES" [Title/Abstract]) OR ("REFERENCE INTERVALS" [Title/Abstract]) from the earliest date available until May 2013. Limits included humans. Categories included Imaging and Radiology. This process was complemented by reviewing citations, searching with Google Scholar, expert referrals and hand-searching. Additional articles were included as they became available.

We combined the outputs from the databases PubMed and ISI Web of Knowledge using a referencing program, Endnote $^{\ominus}$ (Version X5; Thomson Reuters). After duplicate entries were removed, titles of citations were screened for possible inclusion. The titles of potentially relevant studies were reviewed, after which the abstracts and full text articles were examined for possible inclusion. We attempted to find an English copy of the full text article for all of the selected abstracts. Articles were graded as eligible, potentially eligible, or not eligible based on the inclusion and exclusion criteria.

\section{Data extraction and analysis}

We extracted the following data: the year of study, sample size, age range, study setting, sample selection methods, measurements and methods of measurements onto a data extraction form. For each age-group, the sample size with reported summary statistics (i.e., mean, median, centiles, standard deviation, confidence intervals, or standard error) for measurements were also documented.

\section{Quality assurance}

The systematic review was conducted according to the methods of the Cochrane Collaboration [11]. We included all available published reference values of echocardiographic evaluation of the right heart in children and young adults in an attempt to minimise publication bias.

\section{Results}

From the 3096 publications retrieved from the databases, we identified 51 studies for inclusion in this report. 2846 articles were excluded on the basis of title alone, while a further 107 abstracts and 72 articles failed to meet the inclusion criteria. 18 of the 19 foreign language articles were excluded because no English translation was available. We were able to include data from the remaining 


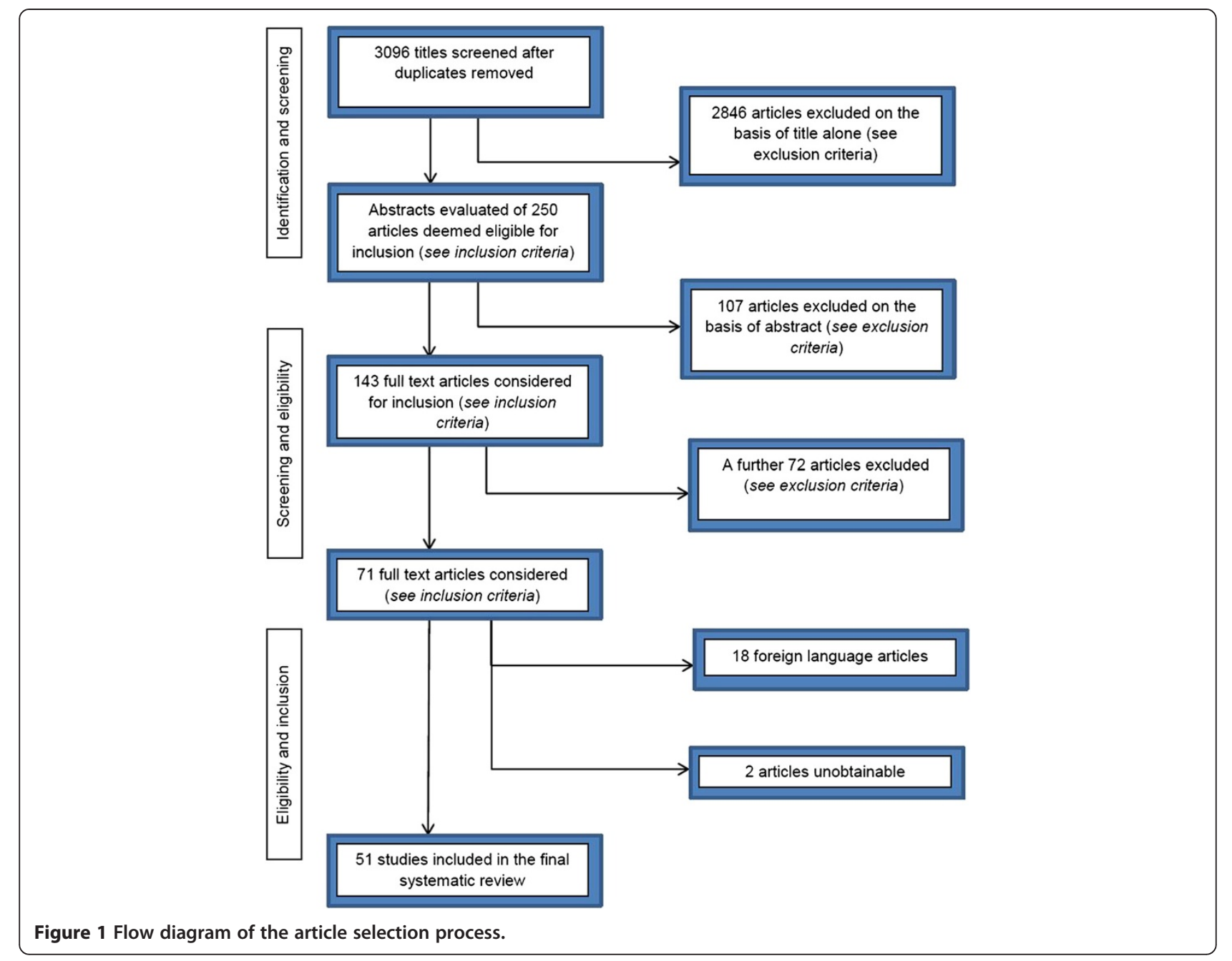

foreign language article as the sub-headings of the tables containing reference data, were in English. Two articles were unobtainable.

\section{Description of studies}

The majority of included studies were conducted in clinical settings (such as hospitals, clinics, or medical centres), and research laboratories. 17 studies did not specify the setting. 15 of the included 51 studies were published before the year 2000, while 36 were published from 2000 onwards. The oldest publication dates back to 1977 [12]. Twenty two studies were from reference populations in North or South America, 17 from European countries, 8 from Asia, 1 from the Middle East, 1 from Australia and 1 from north Africa (Egypt).

The sample size of the reference populations ranged from 13 [13] to 2036 [14]. The ages of the reference populations ranged from 5 to 21 years.

In 24 studies, the reference population consisted of individuals that were referred for echocardiography to exclude cardiac disease $[6,8,9,15-35]$. Nine of the studies presented the reference data of volunteers [12,14,22,36-41]. There were two studies sampling reference participants from wards $[38,42]$, two studies sampled participants from a database(s) $[43,44]$ and one study reported reference values of normal control group [13]. Forteen studies were unclear as to the method of sample selection [45-58]. None of the included studies had a population-based design.

Table 1 summarizes the sample characteristics of all 51 included studies [6,8,9,12-33,35-60]. As the right heart examination should include a measure of the right atrial (RA) and RV size and structure, RV systolic function and pulmonary artery (PA) pressures, [1] our findings are presented in Table 2 (published reference data for right heart size/volume), Table 3 (published reference data for right heart morphology), Tables 4, 5, and 6 (published reference data for RV- and valve function), and Table 7 (published reference data for right heart haemodynamics).

There were insufficient published data for the following measurements: RA size (width, length and area) for children younger than ten years, tricuspid valve (TV) area, RV dimensions (base, mid and length) and -areas 
Table 1 Sample characteristics of the 51 included studies

\begin{tabular}{|c|c|c|c|c|c|c|}
\hline Author & Year & Sampling methods & Sample size & Age-range & Age-categories & Sample size per age-category \\
\hline Ayabakan [15] & 2003 & REF, $V, O$ & 72 & $3 d-16 y$ & 4 & 18 \\
\hline Boettler [45] & 2005 & $U$ & 129 & $1 d-16.9 y$ & 1 & 129 \\
\hline Bonatto [9] & 2006 & REF & 595 & $1 m-144 m$ & \multicolumn{2}{|c|}{ (Data presented according to BSA) } \\
\hline Cantinotti [59] & 2013 & \multicolumn{5}{|c|}{ A review containing nomograms } \\
\hline Cui [16] & 2008 & REF & 593 & $1 d-18 y$ & 1 & 593 \\
\hline Daubeney [17] & 1999 & REF, U & 125 & $1 m-207 m$ & \multicolumn{2}{|c|}{ (Regression equations and Nomograms) } \\
\hline Eidem [36] & 1998 & V & 152 & $3 y-18 y$ & 1 & 152 \\
\hline Eidem [18] & 2004 & REF & 325 & $1 d-18 y$ & 5 & $55-81$ \\
\hline Frommelt [19] & 2002 & REF & 141 & $3 d-18 y$ & 2 & $27 ; 114$ \\
\hline Goebel [37] & 2006 & V & 45 & $5 y-23 y$ & 1 & 45 \\
\hline Gutgesell [20] & 1991 & $U$ & 70 & $1 d-18 y$ & \multicolumn{2}{|c|}{ (Data presented according to BSA) } \\
\hline Hanseus [46] & 1988 & $U$ & 120 & $3 d-15.5 y$ & \multicolumn{2}{|c|}{ (Regression equations and Nomograms) } \\
\hline Harada [21] & 2000 & REF & 48 & $7 d-18 y$ & 1 & 48 \\
\hline Hershenson [60] & 2010 & $U$ & 16 & $5.8 \pm 1.7 y$ & 1 & 16 \\
\hline Hui [44] & 2010 & $\mathrm{O}$ & 103 & $3-18$ yrs & 4 & $19-29$ \\
\hline Ichida [38] & 1987 & $\mathrm{O}, \mathrm{V}$ & 173 & $0 d-15 y$ & 7 & $8-21$ \\
\hline Innelli [22] & 2009 & $R E F, V$ & 40 & $10 y-19 y$ & 1 & 40 \\
\hline Ishii [8] & 2000 & REF & 150 & $30 d-18 y$ & 1 & 150 \\
\hline Jin [23] & 1997 & REF & 108 & $7 d-17 y$ & 5 & $12-29$ \\
\hline Kampmann [14] & 2000 & $R E F, V$ & 2036 & $1 d-18 y$ & \multicolumn{2}{|c|}{ (Data presented according to BSA / weight) } \\
\hline Kapusta [47] & 2000 & V & 160 & $4 y-17.9 y$ & 1 & 160 \\
\hline King [24] & 1985 & REF & 103 & $1 d-15 y$ & \multicolumn{2}{|c|}{ (Data presented according to BSA) } \\
\hline Koestenberger [26] & 2009 & REF & 640 & $1 d-18 y$ & 22 & $18-47$ \\
\hline Koestenberger [25] & 2012 & REF & 860 & $1 m-18 y$ & 29 & $8-83$ \\
\hline & & & & & \multicolumn{2}{|c|}{ (Graphically according to age and BSA) } \\
\hline Kutty [27] & 2013 & REF & 153 & $<1-20 y$ & 5 & $21-24$ \\
\hline & & & & & \multicolumn{2}{|c|}{ (Contour plots as a function of age) } \\
\hline Lange [48] & 1983 & $U$ & 185 & Birth - $15 y$ & \multicolumn{2}{|c|}{ (Data presented according to BSA / weight) } \\
\hline Lester [39] & 1987 & V & 202 & $25 d-23 y$ & \multicolumn{2}{|c|}{ (Data presented according to BSA) } \\
\hline Matsui [49] & 2007 & $U$ & 22 & $1.6-10.8 y$ & 1 & 22 \\
\hline McQuillan [43] & 2001 & O & 856 & $<20 y$ & 1 & 856 \\
\hline Moiduddin [13] & 2010 & O & 13 & $5.7 y \pm 1.8 y$ & 1 & 13 \\
\hline Mori [50] & 2004 & $U$ & 396 & Birth - $19 y$ & 3 & $130-135$ \\
\hline Norgard [51] & 1992 & $U$ & 15 & $6 y-16 y$ & 1 & 15 \\
\hline Nunez-Gil [28] & 2011 & REF & 405 & $0 d-18$ yrs & 9 & $15-77$ \\
\hline & & & & & \multicolumn{2}{|c|}{ (Graphically according to weight, height and BS } \\
\hline Pettersen [29] & 2008 & REF & 782 & 1 day $-18 y$ & \multicolumn{2}{|c|}{ (Data presented according to BSA) } \\
\hline Rafeiyian [30] & 2005 & REF & 100 & $1 m-15 y$ & 4 & $9-46$ \\
\hline Roberson [31] & 2007 & REF & 634 & $1 d-18 y$ & \multicolumn{2}{|c|}{ (Data presented according to BSA) } \\
\hline Roberson [53] & 2007 & $U$ & 308 & $1 d-18 y$ & 6 & $41-77$ \\
\hline Sarnani [32] & 2009 & $U$ & 179 & $0.02 m-19 y$ & 1 & 179 \\
\hline Seguela [33] & 2012 & REF & 50 & $2 m-18 y$ & 1 & 50 \\
\hline Shedeed [40] & 2010 & V & 60 & $5-15 y$ & 1 & 60 \\
\hline Singh [41] & 1994 & V & 78 & $2 m-50 y$ & 4 & $7-47$ \\
\hline
\end{tabular}


Table 1 Sample characteristics of the 51 included studies (Continued)

\begin{tabular}{|c|c|c|c|c|c|c|}
\hline Stines [54] & 2011 & $U$ & 16 & $5.7 \pm 1.7 y$ & 1 & 16 \\
\hline Suleymanoglu [6] & 2007 & REF & 213 & $15 d-15 y$ & \multicolumn{2}{|c|}{ (According to weight and graphically for age) } \\
\hline Van der Hulst [55] & 2011 & $U$ & 123 & $1 m-18 y$ & 5 & (Not presented in tables) \\
\hline Vignola [12] & 1977 & V & 17 & $3 y-17 y$ & 1 & 17 \\
\hline Weidemann [56] & 2002 & U & 33 & $4-16 y$ & 1 & 33 \\
\hline Wessel [57] & 1985 & U & 30 & (Children - ages not stated) & \multicolumn{2}{|c|}{ (Data presented according to weight) } \\
\hline Yusuoka [34] & 1999 & REF & 99 30(TDI) & $7 d-22 y$ & \multicolumn{2}{|c|}{ (Data presented graphically according to age) } \\
\hline Zhendong [58] & 1998 & U & 88 & $3 y-12 y$ & 2 & $41 ; 47$ \\
\hline Zilberman [35] & 2005 & REF & 748 & Birth - $18 y$ & \multicolumn{2}{|c|}{ (Data presented according to BSA) } \\
\hline
\end{tabular}

REF, referred to exclude cardiac disease; $V$, volunteers; $O$, other; $d$, day(s); $y$, year(s); $U$, unknown; $m$, month(s); BSA, body surface area; BS, body surface; TDI, tissue Doppler imaging.

(diastolic and systolic), the RV fractional area change and the RV-to-RA peak pressure gradient. There were no published reference data for the RV mid-cavity dimensions presented as a sub-group for children younger than ten years; PA peak pressure gradient for children older than 12 years; inferior vena cava (IVC) diameter and percentage collapse for children younger than ten years. None of the studies estimated PA systolic pressure using an estimate of RA pressure that was based on the dimension and percentage collapse of the IVC. Lastly, there were no published data for RV volumes and ejection fraction using the area-length method.

\section{Discussion}

While performing this review, we recognized several limitations of available reference data in paediatric echocardiography, including a lack of technical standardization of measurements, inappropriate "normal" subjects and choice of population [6,8,9,15-35], small sample sizes $[12,13,21,22,33,37,49,51,56,60]$ and heterogeneous methods of reporting reference values. A valid metaanalysis could not be performed because of the variability in the populations studied, in the methodology for performing and normalizing measurements, and in ways to express normalized data. These limitations were also reported in a previous review [61].

We consider this review as the most complete report on the availability of reference data in children and young adults, highlighting areas lacking sufficient data with respect to measurements of the RA, the TV, RV size and -function, the pulmonary valve (PV), the PA, and right heart haemodynamics.

\section{Right atrium}

We identified only one publication presenting reference data for RA size for children younger than 10 years of age. In 1988, Hanseus et al. published a set of reference values of the RA on a sample of 120 healthy infants and children, aged three days to 15.5 years. His RA measurements included the width, length and area for the RA. He presented the data for the entire sample according to body surface area(BSA) using regression equations and nomograms [46].

Innelli et al. published a set of reference values for RA width on a sub-group of 40 healthy children and adolescents, aged 10-19 years. In this recent publication, reference values for the entire sub-group, aged 10-19 years were presented as one value [22].

\section{Tricuspid valve area}

Sufficient data exist on the diameter of the TV annulus, but we discovered only one publication presenting reference data on the TV area. Singh et al. published reference values on the TV area based on a reference population aged two months to 50 years. The data for participants less than 16 years were presented in 3 different age-categories [41].

\section{Right ventricle size and/or volume}

We identified one publication presenting reference data for RV basal diameter for children younger than 10 years of age [46]. This two decades old study obtained a reference population of 120 healthy infants and children, aged 3 days to 15.5 years. The data were adjusted for BSA, using regression equations and nomograms [46]. Innelli et al. recently published reference values on a sub-group of 40 healthy children and adolescents, aged 10-19 years as one value [22].

Two publications exist on reference values of the RV mid diameter measured in the apical four-chamber view [22,51]. Norgard et al. presented reference values for RV mid diameter on only 15 individuals, aged 6-16 years as one value for the entire sample [51]. More recently, Innelli et al. published reference values of a sub-group of 40 healthy children and adolescents, aged 10-19 years as one value [22]. We found no publications presenting reference values for RV mid diameter measured in the apical four-chamber view for children younger than 10 years. 
Table 2 Published reference data for right heart size/volume

\begin{tabular}{|c|c|c|c|c|c|c|c|c|c|c|c|}
\hline Measurement & Boettler [45] & Bonatto [9] & Daubeney [17] & Gutgesell [20] & Hanseus [46] & Ichida [38] & Innelli [22] & Jin [23] & Kampmann [14] & King [24] & Lange [48] \\
\hline \multicolumn{12}{|l|}{ Right atrium } \\
\hline Width & & & & & $x$ & & $x$ & & & & \\
\hline Length & & & & & $x$ & & & & & & \\
\hline Area & & & & & $x$ & & & & & & \\
\hline \multicolumn{12}{|l|}{ Tricuspid valve } \\
\hline \multicolumn{12}{|l|}{ Area } \\
\hline Annular diameter & & & $x$ & & & & & & & $x$ & \\
\hline MV-TV distance & & & & & $x$ & & & & & & \\
\hline \multicolumn{12}{|l|}{ Right ventricle } \\
\hline Mid RV & & $x$ & & & & & $x$ & & $x$ & & $x$ \\
\hline RV Base & & & & & $x$ & & $x$ & & & & \\
\hline RV Length & & & $x$ & & $x$ & & $x$ & & & & \\
\hline RV Area & $x$ & & $x$ & & $x$ & & & & & & \\
\hline End-diastolic volume & & & & & & & & $x$ & & & \\
\hline \multicolumn{12}{|l|}{ End-diastolic volume } \\
\hline Muscle volume & & & & & & & & $x$ & & & \\
\hline Muscle volume index & & & & & & & & $x$ & & & \\
\hline \multicolumn{12}{|l|}{ RV geometry } \\
\hline Outflow tract diameter & & $x$ & & $x$ & $x$ & & & & & & \\
\hline Outflow tract length & & & $x$ & & & & & & & & \\
\hline \multicolumn{12}{|l|}{ Pulmonary } \\
\hline Valve area & & & & $x$ & & & & & & & \\
\hline Annulus & & & $x$ & & $x$ & $x$ & & & & & \\
\hline Artery & & & $x$ & & & & & & $x$ & & \\
\hline
\end{tabular}


Table 2 Published reference data for right heart size/volume (Continued)

\begin{tabular}{|c|c|c|c|c|c|c|c|c|c|c|c|}
\hline Measurement & Lange [48] & Lester [39] & Matsui [49] & Norgard [51] & Pettersen [29] & Shedeed [40] & Singh [41] & Suleymanoglu [6] & Vignola [12] & Wessel [57] & Zilberman [35] \\
\hline \multicolumn{12}{|l|}{ Right atrium } \\
\hline \multicolumn{12}{|l|}{ Width } \\
\hline \multicolumn{12}{|l|}{ Length } \\
\hline \multicolumn{12}{|l|}{ Area } \\
\hline \multicolumn{12}{|l|}{ Tricuspid valve } \\
\hline Area & & & & & & & $x$ & & & & \\
\hline Annular diameter & & & & & $x$ & & & & & & $x$ \\
\hline \multicolumn{12}{|l|}{ MV-TV distance } \\
\hline \multicolumn{12}{|l|}{ Right ventricle } \\
\hline Mid RV & $x$ & $x$ & & $x$ & & $x$ & & & $x$ & & \\
\hline \multicolumn{12}{|l|}{ RV Base } \\
\hline RV Length & & & & $x$ & & & & & & & \\
\hline RV Area & & & & $x$ & & & & & & & \\
\hline End-diastolic volume & & & & $x$ & & & & & & & \\
\hline End-diastolic volume & & & & & & & & $x$ & & & \\
\hline \multicolumn{12}{|l|}{ Muscle volume } \\
\hline \multicolumn{12}{|l|}{ Muscle volume index } \\
\hline RV geometry & & & & & & & & & & $x$ & \\
\hline Dutflow tract diameter & & & & $x$ & $x$ & & $x$ & & & & \\
\hline \multicolumn{12}{|l|}{ Outflow tract length } \\
\hline \multicolumn{12}{|l|}{ Pulmonary } \\
\hline \multicolumn{12}{|l|}{ Valve area } \\
\hline Annulus & & & $x$ & & $x$ & & & & & & $x$ \\
\hline Artery & & & & & $x$ & & & & & & \\
\hline
\end{tabular}

$M V$, mitral valve; $T V$, tricuspid valve; $R V$, right ventricle. 
Table 3 Published reference data for right heart morphology

\begin{tabular}{|c|c|c|c|c|c|c|}
\hline Measurement & Hanseus [46] & Kampmann [14] & Kapusta [47] & Lester [39] & Shedeed [40] & Wessel [57] \\
\hline Right Ventricle Anterior Wall thickness & & $x$ & $x$ & $x$ & $x$ & \\
\hline MV-TV distance & $x$ & & & & & \\
\hline RV geometry & & & & & & $x$ \\
\hline
\end{tabular}

MV, mitral valve; $T V$, tricuspid valve; $R V$, right ventricle.

Two publications were found containing reference values of the RV end-systolic area measured in the apical fourchamber view $[45,51]$. The usefulness of both of these publications however, is limited as they both present the data for the entire sample spanning more than 10 years as one value. One study had only 15 individuals, aged 6-16 years [51]. Boettler et al. published reference values of a larger series containing 129 reference individuals, aged 1 day to 16.9 years [45].

Right ventricular function: \% fractional area change and isovolumic acceleration

Only one publication was identified for RV \% fractional area change in a sample of healthy children [13]. The sample of healthy children was a control-group consisting of 13 healthy individuals. One of the objectives of the study was to compare quantitative measurements of the RV in single RV's to normal RV's. The \% fractional area change of the control-group consisting of 13 healthy individuals was presented. The mean age of the healthy control-group was $5.7 \pm 1.8$ years [13]. A study aiming to generate reference values for RV fractional area change, containing a larger sample with greater age-span and categorization may be more useful in clinical practice.

We did not find any existing reference data on isovolumic acceleration.

\section{Pulmonary artery peak pressure gradient}

Zhendong et al. published reference values of the PA peak pressure gradient in 1998 in a reference population consisting of 88 healthy individuals, aged 3-12 years. The sample was divided into two age-categories [58]. No publications were found containing data for children older than 12 years.

\section{Right-sided haemodynamics}

McQuillan et al. have published the only reference data on right-sided haemodynamics for children and adolescents that we could find [43]. This study of 856 participants younger than 20 years published reference data for the TV RV-RA gradient. They presented estimated PA systolic pressure values assuming that the RA pressure for all reference individuals was $10 \mathrm{mmHg}$. The reference data were presented graphically, normalised to BSA [43]. Pena et al. published reference data for the tricuspid regurgitation (TR) peak velocity, but of 55 new-born infants recently [52]. The authors also presented estimated PA systolic pressure values assuming that the RA pressure for all reference individuals was $5 \mathrm{mmHg}$.

No reference values for the diameter and percentage collapse of the IVC for children younger than 10 years were found. Innelli et al. published reference values for the IVC diameter and percent IVC collapse in a subgroup consisting of 40 healthy children and adolescents but presented the data for the entire sample, aged 10-19 years as one value [22].

No reports were found on reference values for estimated PA systolic pressure with an estimate of RA pressure on the basis of IVC size and collapse.

We found sufficient reference data for the following variables: TV annulus, RV length, RV end-diastolic area, RV outflow-tract dimension, PV diameter, PA diameter, tricuspid annulus peak systolic excursion (TAPSE) and tissue myocardial velocities at the lateral tricuspid annulus.

\section{Tricuspid valve annular size}

Four authors have published reference data of the annulus of the TV based on reference populations ranging from infants to young adults, normalised to BSA [17,24,29,35]. The oldest publication was by King et al. in 1985. The most recent publication was by Pettersen et al. in 2008. The sample sizes ranged from the smallest by King $(\mathrm{N}=103)$ to the largest by Pettersen $(\mathrm{N}=782)$.

\section{Right ventricular size: length}

Four existing publications presented reference values for the RV length, measured in the apical four-chamber view $[17,22,46,51]$. Hanseus et al. $(\mathrm{N}=120)$ and Daubeney et al. $(\mathrm{N}=125)$ presented data for the entire sample (birth to adolescent age), according to BSA whereas Inneli et al. $(\mathrm{N}=40$, 10-19years) and Norgard et al. ( $\mathrm{N}=15,6$-16years) presented data for the entire sample, as one value $[17,22,46,51]$.

\section{Right ventricular size: end-diastolic area}

Four authors published reference values for the RV enddiastolic area, measured in the apical four-chamber view [17,45,46,51]. Authors Hanseus et al. $(1988, \mathrm{~N}=120)$ and Daubeney et al. $(1999, \mathrm{~N}=125)$ presented data for the entire sample (birth to adolescent age), normalised to BSA $[17,46]$. Boettler et al. (2005, $\mathrm{N}=120,0$-17years) and Norgard et al. (1992, N = 15, 6-16years) presented data for the entire sample, as one value $[45,51]$. 


\section{Table 4 Published reference data of right ventricular function by 2D and 3D echocardiography}

\begin{tabular}{|c|c|c|c|c|c|c|c|c|c|c|c|}
\hline Measurement & Method & Boettler [45] & Clark [42] & Innelli [22] & $\operatorname{Jin}[23]$ & Koestenberger [26] & Moiduddin [13] & Norgard [51] & Nunez-Gil [28] & Seguela [33] & Suleymanoglu [6] \\
\hline \multicolumn{12}{|c|}{ RV Volume and -output } \\
\hline $\begin{array}{l}\text { End-diastolic } \\
\text { volume }\end{array}$ & 3D echocardiography & & & & & & & & & $x$ & \\
\hline End-systolic volume & & & & & & & & & & $x$ & \\
\hline $\begin{array}{l}\text { End-diastolic } \\
\text { volume }\end{array}$ & Ellipsoid & & $x$ & & & & & & & & \\
\hline End-systolic volume & & & $x$ & & & & & & & & \\
\hline $\begin{array}{l}\text { End-diastolic } \\
\text { volume }\end{array}$ & $\begin{array}{l}\text { Simpson's } \\
\text { single-plane }\end{array}$ & & & & $x$ & & & $x$ & & & $x$ \\
\hline End-systolic volume & & & & & $x$ & & & $x$ & & & $x$ \\
\hline Stroke volume & 3D echocardiography & & & & & & & & & $x$ & \\
\hline Stroke volume & Ellipsoid & & $x$ & & & & & & & & \\
\hline Stroke volume & $\begin{array}{l}\text { Simpson's } \\
\text { single-plane }\end{array}$ & & & & $x$ & & & $x$ & & & \\
\hline$\% F A C$ & & & & & & & $x$ & & & & \\
\hline Ejection fraction & 3D echocardiography & & & & & & & & & $x$ & \\
\hline Ejection fraction & Ellipsoid & & $x$ & & & & & & & & \\
\hline Ejection fraction & $\begin{array}{l}\text { Simpson's } \\
\text { single-plane }\end{array}$ & $x$ & & & $x$ & & & $x$ & & & \\
\hline RV output & Ellipsoid & & $x$ & & & & & & & & \\
\hline TAPSE & & & & $x$ & & $x$ & & & $x$ & & \\
\hline
\end{tabular}

$\overline{R V}$, right ventricle; $3 D$, three-dimensional; \%FAC, percentage fractional area change; TAPSE, tricuspid annular peak systolic excursion. 
Table 5 Published reference data of right ventricular function by pulsed Doppler velocities and time-intervals

\begin{tabular}{|c|c|c|c|c|c|c|c|c|c|c|}
\hline Measurement & Ayabakan [15] & Cantenotti [59] & Cui [16] & Eidem [36] & Eidem [18] & Frommelt [19] & Hershenson [60] & Innelli [22] & Ishii [8] & Kapusta [47] \\
\hline Tricuspid systolic annular acceleration & & & & & & $x$ & & & & \\
\hline Tricuspid deceleration time & & & & & & $x$ & & & & \\
\hline RV myocardial performance index & & $x$ & & $x$ & $x$ & & & & $x$ & \\
\hline Tricuspid E velocity & & $x$ & & & $x$ & & $x$ & $x$ & & $x$ \\
\hline Tricuspid A velocity & & $x$ & & & $x$ & & $x$ & $x$ & & $x$ \\
\hline E: A ratio & & $x$ & & & $x$ & & & $x$ & $x$ & $x$ \\
\hline \multicolumn{11}{|l|}{ A: E ratio } \\
\hline \multicolumn{11}{|l|}{ E and $A$ VTI } \\
\hline \multicolumn{11}{|l|}{$\mathrm{A} \vee \mathrm{VTI}$} \\
\hline \multicolumn{11}{|l|}{ E flow velocity integral } \\
\hline \multicolumn{11}{|l|}{ A flow velocity integral } \\
\hline \multicolumn{11}{|l|}{ Tricuspid inflow area } \\
\hline \multicolumn{11}{|l|}{$\%$ Atrial fraction } \\
\hline Presence of TR & & & & & & & & & $x$ & \\
\hline RV outflow velocity & & & & & & & & $x$ & & \\
\hline \multicolumn{11}{|l|}{ RV VTI } \\
\hline Peak tricuspid velocity & & & & & & & & & & $x$ \\
\hline Late diastolic velocity and VTI & $x$ & & & & & & & & & \\
\hline Peak systolic flow and VTI & $x$ & & & & & & & & & \\
\hline Peak diastolic flow and VTI & $x$ & & & & & & & & & \\
\hline Peak reverse atrial flow - $\mathrm{R}$ wave on ECG & $x$ & & & & & & & & & \\
\hline $\mathrm{R}$ wave on ECG - peak diastolic flow & $x$ & & & & & & & & & \\
\hline Peak diastolic flow - peak reverse atrial flow & $x$ & & & & & & & & & \\
\hline RV isovolumic times & & & & $x$ & & & & & $x$ & \\
\hline \multicolumn{11}{|l|}{ RV systolic duration } \\
\hline \multicolumn{11}{|l|}{ RV diastolic duration } \\
\hline RV systolic duration: RV diastolic duration & & & & & & & & & & \\
\hline
\end{tabular}


Table 5 Published reference data of right ventricular function by pulsed Doppler velocities and time-intervals (Continued)

\begin{tabular}{|c|c|c|c|c|c|c|c|c|c|}
\hline Measurement & Moiduddin [13] & Mori [50] & Roberson [53] & Sarnari [32] & Shedeed [40] & Singh [41] & Stines [54] & Yasuoka [34] & Zhendong [58] \\
\hline \multicolumn{10}{|l|}{ Tricuspid systolic annular acceleration } \\
\hline \multicolumn{10}{|l|}{ Tricuspid deceleration time } \\
\hline RV myocardial performance index & & & $x$ & & & & & & \\
\hline Tricuspid E velocity & & $x$ & & & $x$ & & & $x$ & $x$ \\
\hline Tricuspid A velocity & & $x$ & & & $x$ & & $x$ & $x$ & $x$ \\
\hline E: A ratio & & & & & $x$ & & $x$ & $x$ & $x$ \\
\hline A: E ratio & & $x$ & & & & & & & \\
\hline $\mathrm{E}$ and $\mathrm{A} V \mathrm{VTI}$ & & & & & & $x$ & $x$ & & \\
\hline $\mathrm{A} \vee \mathrm{VTI}$ & & & & & & & $x$ & & \\
\hline E flow velocity integral & & & & & & & & $x$ & \\
\hline A flow velocity integral & & & & & & & & $x$ & \\
\hline Tricuspid inflow area & & & & & & & & $x$ & \\
\hline$\%$ Atrial fraction & & & & & & & $x$ & & \\
\hline \multicolumn{10}{|l|}{ Presence of TR } \\
\hline RV outflow velocity & & & & & & & & & $x$ \\
\hline RV VTI & & & & & & $x$ & & & \\
\hline Peak tricuspid velocity & & & & & & & & & $x$ \\
\hline \multicolumn{10}{|l|}{ Late diastolic velocity and VTI } \\
\hline \multicolumn{10}{|l|}{ Peak systolic flow and VTI } \\
\hline \multicolumn{10}{|l|}{ Peak diastolic flow and VTI } \\
\hline \multicolumn{10}{|l|}{ Peak reverse atrial flow - $R$ wave on ECG } \\
\hline \multicolumn{10}{|l|}{ R wave on ECG - peak diastolic flow } \\
\hline \multicolumn{10}{|l|}{ Peak diastolic flow - peak reverse atrial flow } \\
\hline $\mathrm{RV}$ isovolumic times & $x$ & & $x$ & & & & & & \\
\hline RV systolic duration & & & & $x$ & & & & & \\
\hline RV diastolic duration & & & & $x$ & & & & & \\
\hline RV systolic duration: RV diastolic duration & & & & $\mathrm{x}$ & & & & & \\
\hline
\end{tabular}

$R V$, right ventricle; $E$, early diastole/diastolic; A, late diastole/diastolic; VTI, velocity time integral; \%, percentage; $T R$, tricuspid regurgitation; ECG, electrocardiograph. 
Table 6 Published reference data of right ventricular function by tissue Doppler and strain

\begin{tabular}{|c|c|c|c|c|c|c|c|c|c|c|c|c|c|c|}
\hline Measurement & & View & Sample volume & $\begin{array}{c}\text { Boettler } \\
\text { [45] }\end{array}$ & $\begin{array}{c}\text { Cantenotti } \\
\text { [59] }\end{array}$ & $\begin{array}{l}\text { Cui } \\
{[16]}\end{array}$ & $\begin{array}{c}\text { Eidem } \\
\text { [36] }\end{array}$ & $\begin{array}{c}\text { Eidem } \\
\text { [18] }\end{array}$ & $\begin{array}{c}\text { Frommelt } \\
{[19]}\end{array}$ & $\begin{array}{c}\text { Goebel } \\
\text { [37] }\end{array}$ & $\begin{array}{c}\text { Harada } \\
\text { [21] }\end{array}$ & $\begin{array}{c}\text { Hershenson } \\
{[60]}\end{array}$ & $\begin{array}{l}\text { Hui } \\
{[44]}\end{array}$ & $\begin{array}{c}\text { Innelli } \\
\text { [22] }\end{array}$ \\
\hline RV dyssynchrony/delay & & & & & & & & & & & $\mathrm{x}$ & $\mathrm{x}$ & & \\
\hline RV Tissue displacement & & & & & & & & & $x$ & & & & & \\
\hline \multicolumn{15}{|c|}{ Tissue Doppler velocites and time-intervals } \\
\hline Sa; Ea; Aa; Ea: Aa; Aa: Ea & $\mathrm{A} 4 \mathrm{C}$ & TV annulus & & $x$ & & & $x$ & $x$ & $x$ & $x$ & $x$ & & $x$ & $x$ \\
\hline Sa; Ea; Aa; Ea: Aa; Ea: Sa & PLAX & RV anterior wall & & & & & & & & & & & & $x$ \\
\hline Sa & PSAX & RV outflow tract & & & & & & & & & & & & \\
\hline Isovolumic times & & & & & $x$ & $x$ & $x$ & $x$ & $x$ & & & & $x$ & \\
\hline \multicolumn{15}{|l|}{ Deceleration time } \\
\hline Systolic and diastolic tim & & & $x$ & & $x$ & & & & & & & & & \\
\hline Myocardial performance ir & & & & $x$ & $x$ & & & & & & $x$ & & & \\
\hline E (pulsed Doppler): Ea ra & & & & $x$ & & & $x$ & & & & $x$ & & $x$ & \\
\hline \multicolumn{15}{|c|}{ Strain } \\
\hline Ss, Se, Sa & $\mathrm{A} 4 \mathrm{C}$ & RV free wall & $x$ & & & & & & & & & & & \\
\hline RV inflow & SC RAO & RV inferior wall & & & & & & & & & & & & \\
\hline RV outflow & SC RAO & RV free wall & & & & & & & & & & & & \\
\hline Pulmonary annulus & SC RAO & RV free wall & & & & & & & & & & & & \\
\hline Ss, Se, Sa & $\mathrm{A} 2 \mathrm{C}$ & RV inferior wall & & & & & & & & & & & & \\
\hline Se and Sa duration & & RV free wall & $x$ & & & & & & & & & & & \\
\hline \% RV Strain & & & & & & & & & $x$ & & & & & \\
\hline \multicolumn{15}{|l|}{ RV Time to peak strain } \\
\hline \multicolumn{15}{|l|}{ Strain rate } \\
\hline \multicolumn{15}{|l|}{ Right atrial strain } \\
\hline RV strain & $\mathrm{A} 4 \mathrm{C}$ & RV free wall & $x$ & & & & & & $x$ & & & & & \\
\hline RV strain & $\mathrm{A} 2 \mathrm{C}$ & RV inferior wall & & & & & & & & & & & & \\
\hline
\end{tabular}


Table 6 Published reference data of right ventricular function by tissue Doppler and strain (Continued)

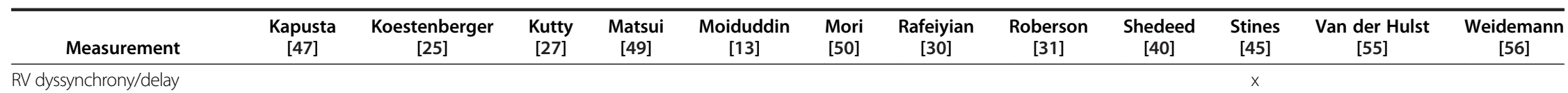

RV Tissue displacement

Tissue Doppler velocites and time-intervals

Sa; Ea; Aa; Ea: Aa; Aa: Ea

$x$

Sa; Ea; Aa; Ea: Aa; Ea: Sa

Sa

Isovolumic times

Deceleration time

Systolic and diastolic times

Myocardial performance index

E (pulsed Doppler): Ea ratio

Strain

Ss, Se, Sa

RV inflow

RV outflow

Pulmonary annulus

$\mathrm{Ss}, \mathrm{Se}, \mathrm{Sa}$

Se and Sa duration

$\%$ RV Strain

RV Time to peak strain

Strain rate

Right atrial strain

RV strain

RV strain

$R V$, right ventricle: Sa, peak systolic velocity; Ea, early diastolic velocity; Aa, late diastolic velocity; A4C apical four-chamber: TV, tricuspid valve: PLAX, parasternal long-axis: PSAX, parasternal short-axis: E, early diastolic velocity by pulsed Doppler; Ea, tissue Doppler early diastolic myocardial velocity; Ss, peak systolic strain; Se, peak early diastolic strain; Sa, late diastolic peak strain; SC RAO, subcostal right anterior oblique; A2C, apical two-chamber. 


\section{Table 7 Published reference data for right heart haemodynamics}

\begin{tabular}{|c|c|c|c|c|c|c|c|c|c|c|c|c|c|c|}
\hline MMeasurement & Method & $\begin{array}{l}\text { Cantenotti } \\
\text { [59] }\end{array}$ & $\begin{array}{l}\text { Cui } \\
{[16]}\end{array}$ & $\begin{array}{c}\text { Daubeney } \\
\text { [17] }\end{array}$ & $\begin{array}{l}\text { Eidem } \\
\text { [36] }\end{array}$ & $\begin{array}{c}\text { Eidem } \\
\text { [18] }\end{array}$ & $\begin{array}{l}\text { Hershenson } \\
\text { [60] }\end{array}$ & $\begin{array}{c}\text { Innelli } \\
\text { [22] }\end{array}$ & $\begin{array}{l}\text { Ishii } \\
{[8]}\end{array}$ & $\underset{[14]}{\text { Kampmann }}$ & $\begin{array}{c}\text { McQuillan } \\
\text { [43] }\end{array}$ & $\begin{array}{l}\text { Mori } \\
{[50]}\end{array}$ & $\begin{array}{l}\text { Pettersen } \\
\text { [29] }\end{array}$ & $\begin{array}{c}\text { Roberson } \\
\text { [53] }\end{array}$ \\
\hline \multicolumn{15}{|c|}{ Time intervals } \\
\hline \multirow[t]{2}{*}{ PV ejection period } & CW/PW Doppler & & & & $x$ & & & $x$ & $x$ & & & & & $x$ \\
\hline & Tissue Doppler & & $x$ & & & & & & & & & & & \\
\hline $\begin{array}{l}\text { PV pre-ejection } \\
\text { period }\end{array}$ & CW/PW Doppler & & & & $x$ & & & & & & & & & \\
\hline \multicolumn{15}{|c|}{ Pulmonary artery diameter } \\
\hline PA diameter & PSAX & & & $x$ & & & & & & & & & $x$ & \\
\hline PA diameter & Unspecified & & & & & & & & & $x$ & & & & \\
\hline \multicolumn{15}{|c|}{ Right atrial pressures } \\
\hline E/Ea & & $x$ & & & & $x$ & $x$ & $x$ & & & & $x$ & & \\
\hline \multicolumn{15}{|c|}{ RV Systolic pressures } \\
\hline RV-RA gradient & & & & & & & & & & & $x$ & & & \\
\hline \multicolumn{15}{|c|}{ Pulmonary arterial systolic pressures } \\
\hline PASP & RAP $10 \mathrm{mmHg}$ & & & & & & & & & & $x$ & & & \\
\hline \multicolumn{15}{|c|}{ Inferior VENA CAVA } \\
\hline IVC \% collapse & & & & & & & & $x$ & & & & & & \\
\hline IVC diameter & & & & & & & & $x$ & & & & & & \\
\hline
\end{tabular}

$P V$, pulmonary valve; $C W$, continuous wave; $P W$, pulsed wave; $P A$, pulmonary artery; $P S A X$, parasternal short-axis; $E$, early diastolic velocity; Ea, tissue Doppler early diastolic myocardial velocity; RV, right ventricle; RA, right atrium; PASP, pulmonary artery systolic pressure; RAP, right atrium pressure; IVC, inferior vena cava; \%, percentage. 


\section{Right ventricular size: outflow tract dimension}

There are six existing publications reporting the dimension of the RV outflow tract, measured anterior to the aortic valve in the parasternal short-axis view [9,20,29,41,46,51]. The oldest publication dates back to 1988 [46] and the most recent publication was published in 2008 [29]. The sample sizes range from 15 [51] to 782 [29]. The ages of the samples range from birth to adolescent ages. Four authors presented data according to BSA $[9,20,29,46]$. Singh et al. divided the sample into 3 age-categories for children younger than 16 years [41]. Norgard and Vik-Mo published reference data for the entire sample (aged 6-16years) as one value [51].

\section{Pulmonary valve diameter}

Six publications reported reference values for the pulmonary valve PV diameter in children and adolescents [17,29,35,38,46,49]. Hanseus et al., Daubeney et al., Pettersen et al. and Zilberman et al. reported reference values for PV diameter in samples of healthy children ranging from birth to adolescent age and presented the data according to BSA $[17,29,35,46]$. Ichida et al. presented a set of reference intervals for children aged from birth to 15 years stratified by different age-categories [38]. Matsui et al. presented the measured PV diameter in a sample of 22 healthy children, aged 0-11 years as one reference interval [49]. The oldest study dates back to 1987 [38] while the most recent publication was in 2008 [29]. The sample sizes for these publications range from the 22 to 782 .

\section{Pulmonary artery diameter}

Daubeney et al., Pettersen et al. and Kampmann et al. published reference data on the diameter of the PA in children ranging from infancy to adolescent age $[14,17,29]$. The sample sizes were 125, 782 and 2036 respectively. All three authors presented the results according to BSA.

\section{Right ventricular function: tricuspid annulus peak systolic excursion}

Three recent publications detailed reference values for tricuspid annulus peak systolic excursion (TAPSE) in children [22,26,28]. The first publication by Innelli et al. presented the TAPSE values for a sub-group of 40 children and adolescents, aged 10-19 years [22]. The second publication by Koestenberger et al. presented the TAPSE values in a large sample $(\mathrm{N}=640)$ of infants, children and adolescents [26]. The third publication by Nunez et al. presented the TAPSE values in a sample of 405 infants, children and adolescents [28]. The data were presented according to BSA and age-categories.

\section{Right ventricular function: tissue myocardial velocities at the lateral tricuspid annulus}

There are 16 publications containing reference values for tissue myocardial velocities of the lateral tricuspid annulus in the apical four-chamber view $[18,19,21,22,25,30,31,34,37,40,47,50,54,55,59,60]$. The sample size for these publications ranged from $16[54,60]$ to 860 [25]. Seven studies presented data for the entire sample as a single value $[21,22,37,40,47,54,60]$. Koestenberger et al. [25] and Roberson et al. [31] presented reference data according to BSA.

\section{Conclusions}

In the clinical diagnosis and management of patients with cardiopulmonary disorders, arrhythmogenic right ventricular dysplasia and congenital heart disease, the evaluation of the RV is of major importance.

Echocardiography is considered a cornerstone in the diagnosis and management of RV failure. Moreover, it is a leading technology, is less costly, is non-invasive and offers the advantages of wide applicability and availability when compared with other imaging modalities.

Clinically reliable reference data are lacking for important echocardiographic measurements of the RV in children and adolescents. There were insufficient published data of the following variables: RA size (width, length and area) for children younger than 10 years, TV area, RV dimensions (base, mid and length) and areas (diastolic and systolic), the RV percentage fractional area change and the RV-to-RA peak pressure gradient. There were no published reference data for the RV mid-cavity dimensions presented as a subgroup for children younger than 10 years; RV volumes and ejection fraction using the area-length method; PA peak pressure gradient for children older than 12 years; and IVC diameter and -percentage collapse for children younger than 10 years. None of the studies estimated systolic PA pressure using an estimate of RA pressure that was based on the dimension and percentage collapse of the IVC.

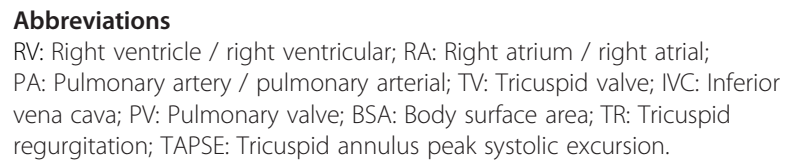

\section{Competing interests}

The authors declared that they have no competing interests.

\section{Authors' contributions}

BMM conceived of the study and agreed to oversee its design and coordination, together with MEE and JCS. Under the guidance of MEE, CEL obtained and screened all the articles for this review. CEL extracted and summarized the data and drafted the manuscript. BMM, MEE and JCS revised the manuscript critically for important intellectual content and gave final approval of the version to be published. All authors read and approved the final manuscript.

\section{Acknowledgements}

The help, support, patience and understanding of our families made this possible. Thank you.

\section{Author details}

${ }^{1}$ Department of Medicine, University of Cape Town and Groote Schuur Hospital, Observatory, Cape Town, South Africa. ${ }^{2}$ National Health Laboratory 
Service and Department of Chemical Pathology, University of KwaZulu-Natal, Durban, South Africa.

Received: 5 December 2013 Accepted: 14 January 2014 Published: 29 January 2014

\section{References}

1. Rudski LG: Guidelines for the Echocardiographic Assessment of the Right Heart in Adults: a report from the American Society of Echocardiography Endorsed by the European Association of Echocardiography, a registered branch of the European Society of Cardiology, and the Canadian Society of Echocardiography. J Am Soc Echocardiogr 2010, 23:685-713.

2. Lipschultz SEM, Miller TL: Establishing norms for echocardiographic measurements of cardiovascular structures and function in children. J Appl Physiol 2005, 99:386-388.

3. Haddad FH, Hunt SA, Rosenthal DN, Murphy DJ: Right ventricular function in cardiovascular disease, part I: anatomy, physiology, aging, and functional assessment of the right ventricle. Circulation 2008, 117:1436-1448.

4. Poelaert J: The Role of Echocardiography in the Management of Right Ventricular Failure. 2006. cited 2009 March; Wintersymposium. Available from: http://www. kuleuven.be/anesthesie/congressen/2006/friday/kul2006_poelaert.pdf.

5. Ionescu A: The echocardiographic assessment of the right heart in the adult an overview for echocardiographers. Prepared as educational material for the BSE. cited 2009 March; Available from: www.pdfbro.com/ebook/190254-dlm10-right-heart-text.html.

6. Suleymanoglu S, et al: Determination of normal echocardiographic values for right ventricular volume in children with two-dimensional transthoracic echocardiography. Turk J Pediatr 2007, 49(2):141-147.

7. Lopez $L$ : Recommendations for quantification methods during the performance of a pediatric echocardiogram: a report from the pediatric measurements writing group of the American society of Echocardiography Pediatric and Congenital heart disease council. J Am Soc Echocardiogr 2010, 23:465-495.

8. Ishii $\mathrm{M}$, et al: Quantitation of the global right ventricular function in children with normal heart and congenital heart disease: a right ventricular myocardial performance index. Pediatr Cardiol 2000, 21(5):416-421.

9. Bonatto RC, et al: Percentile curves of normal values of echocardiographic measurements in normal children from the central-southern region of the State of Sao Paulo, Brazil. Ara Bras Cardiol 2006, 87(6):711-721

10. Cook DJS, Sacket DL, Spitzer WO: Methodologic guideline for systematic reviews of randomized control trials in health care from the potsdam consultation on meta-analysis. J Clin Epidemio/ 1995, 48(1):167-171.

11. Higgins JPT, Green S: Cochrane handbook for systematic reviews of interventions 4.2.6 [Updated September 2006]. In The Cochrane Library, Issue 4. Chichester, UK: John Wiley \& Sons, Ltd; 2006.

12. Vignola PA, et al: Interobserver variability in echocardiography. J Clin Ultrasound 1977, 5(4):238-242.

13. Moiduddin N, et al: Two-dimensional speckle strain and dyssynchrony in single right ventricles versus normal right ventricles. J Am Soc Echocardiogr 2010, 23(6):673-679.

14. Kampmann C, et al: Normal values of M mode echocardiographic measurements of more than 2000 healthy infants and children in central Europe. Heart 2000, 83(6):667-672.

15. Ayabakan C, Ozkutlu S: Normal patterns of flow in the superior caval, hepatic and pulmonary veins as measured using Doppler echocardiography during childhood. Cardiol Young 2003, 13(2):143-151.

16. Cui $W$, et al: Systolic and diastolic time intervals measured from Doppler tissue imaging: normal values and Z-score tables, and effects of age, heart rate, and body surface area. J Am Soc Echocardiogr 2008, 21(4):361-370

17. Daubeney PEF, et al: Relationship of the dimension of cardiac structures to body size: an echocardiographic study in normal infants and children. Cardiol Young 1999, 9(4):402-410.

18. Eidem BW, et al: Impact of cardiac growth on Doppler tissue imaging velocities: a study in healthy children. J Am Soc Echocardiogr 2004, 17(3):212-221.

19. Frommelt PCB, Ballweg JA, Whitstone BN, Frommelt MA: Usefulness of Doppler tissue imaging analysis of tricuspid annular motion for determination of right ventricular function in normal infants and children. Am J Cardiol 2002, 89:610-613.
20. Gutgesell HP, French M: Echocardiographic determination of aortic and pulmonary valve areas in subjects with normal hearts. Am J Cardiol 1991, 68(8):773-776

21. Harada KO, Orino T, Yasuoka K, Tamura M, Takada G: Tissue Dopple imaging of left and right ventricles in normal children. Tohoku J Exp Med 2000, 191:21-29.

22. Innelli $P$, et al: The impact of ageing on right ventricular longitudinal function in healthy subjects: a pulsed tissue Doppler study. Eur J Echocardiogr 2009, 10(4):491-498.

23. Jin Z, et al: Cross-sectional echocardiographic determination of right ventricular volume and myocardial mass in children. Normal values and values in children with interatrial communication. Cardiol Young 1997, 7(3):302-309.

24. King $\mathrm{DH}$, et al: Mitral and tricuspid valve anular diameter in normal children determined by two-dimensional echocardiography. Am J Cardiol 1985, 55(6):787-789.

25. Koestenberger $M$, et al: Reference values of tricuspid annular peak systolic velocity in healthy pediatric patients, calculation of $z$ score, and comparison to tricuspid annular plane systolic excursion. Am J Cardiol 2012, 109(1):116-121.

26. Koestenberger $M$, et al: Right Ventricular Function in Infants, Children and Adolescents: Reference Values of the Tricuspid Annular Plane Systolic Excursion (TAPSE) in 640 Healthy Patients and Calculation of z Score Values. J Am Soc Echocardiogr 2009, 22(6):715-719.

27. Kutty S, et al: Functional Maturation of Left and Right Atrial Systolic and Diastolic Performance in Infants, Children, and Adolescents. J Am Soc Echocardiogr 2013, 26(4):398.

28. Nunez-Gil IJ, et al: Determination of normalized values of the tricuspid annular plane systolic excursion (TAPSE) in 405 Spanish children and adolescents. Rev Esp Cardiol 2011, 64(8):674-680.

29. Pettersen MD, et al: Regression equations for calculation of $z$ scores of cardiac structures in a large cohort of healthy infants, children, and adolescents: an echocardiographic study. J Am Soc Echocardiogr 2008, 21(8):922-934.

30. Rafeivian $\mathrm{S}$, et al: Pulse tissue Doppler analysis of tricuspid annular motion in Iranian children. Int J Cardiovasc Imaging 2006, 22(3-4):363-367.

31. Roberson DA, et al: Annular and septal doppler tissue imaging in children: normal Z-score tables and effects of age, heart rate, and body surface area. J Am Soc Echocardiogr 2007, 20(11):1276-1284.

32. Sarnari $R$, et al: Doppler assessment of the ratio of the systolic to diastolic duration in normal children: relation to heart rate, age and body surface area. J Am Soc Echocardiogr 2009, 22(8):928-932.

33. Seguela $P E$, et al: Feasibility of three-dimensional transthoracic echocardiography to evaluate right ventricular volumes in children and comparison to left ventricular values. Echocardiography 2012 29(4):492-501.

34. Yasuoka KH, Harada K, Orino T, Takada G: Right ventricular diastolic filling assessed by conventional Doppler and tissue doppler imaging in normal children. Tohoku J Exp Med 1999, 189:283-294

35. Zilberman MV, Khoury PR, Kimball RT: Two-dimensional echocardiographic valve measurements in healthy children: gender-specific differences. Pediatr Cardiol 2005, 26(4):356-360.

36. Eidem BW, et al: Nongeometric quantitative assessment of right and left ventricular function: myocardial performance index in normal children and patients with Ebstein anomaly. J Am Soc Echocardiogr 1998, 11(9):849-856.

37. Goebel B, et al: Exercise tissue Doppler echocardiography with strain rate imaging in healthy young individuals: feasibility, normal values and reproducibility. Int J Cardiovasc Imaging 2007, 23(2):149-155.

38. Ichida F, et al: Cross sectional echocardiographic assessment of great artery diameters in infants and children. Br Heart J 1987, 58(6):627-634

39. Lester $L A$, et al: M-mode echocardiography in normal children and adolescents: some new perspectives. Pediatr Cardiol 1987, 8(1):27-33.

40. Shedeed SA: Right ventricular function in children with bronchial asthma: a tissue Doppler echocardiographic study. Pediatr Cardiol 2010, 31(7):1008-1015.

41. Singh B, Mohan JC: Atrioventricular valve orifice areas in normal subjects: determination by cross-sectional and Doppler echocardiography. Int $J$ Cardiol 1994, 44(1):85-91.

42. Clark SJ, Yoxall CW, Subhedar NV: Measurement of right ventricular volume in healthy term and preterm neonates. Arch Dis Child 2002, 87(2):F89-F93.

43. McQuillan BM, et al: Clinical correlates and reference intervals for pulmonary artery systolic pressure among echocardiographically normal subjects. Circulation 2001, 104(23):2797-2802. 
44. Hui W, et al: Measurement of right ventricular mechanical synchrony in children using tissue Doppler velocity and two-dimensional strain imaging. J Am Soc Echocardiogr 2010, 23(12):1289-1296.

45. Boettler $P$, et al: Heart rate effects on strain and strain rate in healthy children. J Am Soc Echocardiogr 2005, 18(11):1121-1130.

46. Hanseus K, Bjorkhem G, Lundstrom NR: Dimensions of cardiac chambers and great vessels by cross-sectional echocardiography in infants and children. Pediatr Cardiol 1988, 9(1):7-15.

47. Kapusta $L$, et al: Assessment of myocardial velocities in healthy children using tissue Doppler imaging. Ultrasound Med Biol 2000, 26(2):229-237.

48. Lange L, Fabecicsabadi V, Bein G: Comparative overview of normal echocardiographic values for children ranging from premature newborn to adolescent. Herz 1983, 8(2):105-121.

49. Matsui HS, Satomi G, Yasukochi S, Kaneko S, Haseyama K: Evaluation of right ventriclar contraction by myocardial strain in children using a two-dimensional tissue tracking method. Pediatr Cardiol 2007, 29:377-381.

50. Mori K, et al: Pulsed wave Doppler tissue echocardiography assessment of the long axis function of the right and left ventricles during the early neonatal period. Heart 2004, 90(2):175-180.

51. Norgard G, Vikmo H: Effects of respiration on right ventricular size and function - an echocardiographic study. Pediatr Cardiol 1992, 13(3):136-140.

52. Pena $J$, et al: Quantification of regional left and right ventricular deformation indices in healthy neonates by using strain rate and strain imaging. J Am Soc Echocardiogr 2009, 22(4):369-375.

53. Roberson DA, Cui W: Right ventricular Tei index in children: effect of method, age, body surface area, and heart rate. J Am Soc Echocardiogr 2007, 20(6):764-770.

54. Stines JR, et al: Echocardiographic assessment of atrial properties in single ventricles vs. normal controls. Congenit Heart Dis 2011, 6(3):247-252.

55. van der Hulst AE, et al: Tissue Doppler imaging in the left ventricle and right ventricle in healthy children: normal age-related peak systolic velocities, timings, and time differences. Eur J Echocardiogr 2011, 12(12):953-960.

56. Weidemann FEA: Quantification of regional left and right ventricular radial and longitudinal function in healthy children using ultrasound-based strain rate and strain imaging. J Am Soc Echocardiogr 2002, 15(1):20-28.

57. Wessel A: Normal values of two-dimensional echocardiographic evaluation of left and right ventricular geometry in children. Herz 1985, 10(4):248-254.

58. Zhendong Y: Effects of Age and respiration on right ventricular diastolic filling patterns in normal children. Pediatr Cardiol 1998, 19:218-220.

59. Cantinotti M, Lopez L: Nomograms for blood flow and tissue Doppler velocities to evaluate diastolic function in children: a critical review. J Am Soc Echocardiogr 2013, 26(2):126-141.

60. Hershenson JA, et al: Differences in tissue Doppler imaging between single ventricles after the fontan operation and normal controls. Am J Cardiol 2010, 106(1):99-103.

61. Mawad W, et al: A review and critique of the statistical methods used to generate reference values in pediatric echocardiography. J Am Soc Echocardiogr 2013, 26(1):29-37.

doi:10.1186/1476-7120-12-3

Cite this article as: Lemmer (Hunsinger) et al:: Reference intervals for the echocardiographic measurements of the right heart in children and adolescents: a systematic review. Cardiovascular Ultrasound 2014 12:3.

\section{Submit your next manuscript to BioMed Central and take full advantage of:}

- Convenient online submission

- Thorough peer review

- No space constraints or color figure charges

- Immediate publication on acceptance

- Inclusion in PubMed, CAS, Scopus and Google Scholar

- Research which is freely available for redistribution

Submit your manuscript at www.biomedcentral.com/submit
( Biomed Central 